\title{
Comportamento da palha de cana-de-açúcar submetida ao corte por meio de ensaios de bancada ${ }^{1}$
}

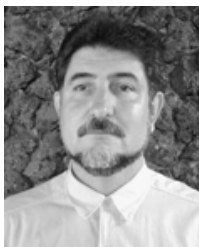

Aloisio Bianchini² \& Paulo S. G. Magalhães ${ }^{3}$

\author{
1 Parte da Tese de Doutor do primeiro autor apresentada na UNICAMP \\ 2 Departamento de solos e Eng. Rural - FAMEV/UFMT, E-mail: bianchi@cpd.ufmt.br (Foto) \\ ${ }^{3}$ Faculdade de Engenharia Agrícola - UNICAMP. Fone: (19) 3788-1053. E-mail: paulo@agr.unicamp.br
}

Protocolo 196 - 30/12/2002 - Aprovado em 16/2/2004

\begin{abstract}
Resumo: Do ponto de vista da engenharia, poucos trabalhos a respeito do corte de restos culturais têm sido publicados, sendo escassas, portanto, as informações sobre o assunto. Sendo assim, este trabalho objetivou-se, estudar o comportamento da palha da cana-de-açúcar quanto ao corte, em função de sua umidade, espessura de sua camada e do ângulo oblíquo da lâmina. Para a coleta de dados foram utilizados um transdutor de força, acoplado á base das lâminas, e um sistema automático de coleta de dados, que trabalhou com taxa de aquisição de $9600 \mathrm{~Hz}$. Os resultados demonstraram diferença significativa na força requerida quando se varia o ângulo oblíquo da lâmina e tendência linear desta força, com o aumento da quantidade de palha, entre 4 e $16 \mathrm{t} \mathrm{ha}^{-1}$. Verificou-se, também, que o requerimento de força e a demanda de energia, quando se variou a umidade da palha, apresentaram comportamento exponencial sendo que, acima de $28 \%$, em base seca, as diferenças para a força de corte requerida e para a demanda de energia passaram a não ser mais significativas. A força máxima de corte apresentou tendência linear e inversamente proporcional ao ângulo oblíquo da lâmina.
\end{abstract}

Palavras-chave: mecanização, palhiço, força de corte

\section{Behavior of sugarcane trash submitted to shearing in laboratory conditions}

\begin{abstract}
From an engineering standpoint, few papers on crop residue shearing have been published, especially with respect to sugarcane and information on the subject is scarce. Therefore, the objective of this work was to study the behavior of sugarcane trash submitted to shearing, as a function of its moisture content, thickness of trash layer and the oblique angle of the blade. A strength transducer, connected to the base of the blades and to an automatic data logger, was utilized to collect data, working at an acquisition rate of $9600 \mathrm{~Hz}$. Results showed significant differences in the required strength when the oblique angle of the blade is changed, and a linear trend with the amount of trash between 4 and $16 \mathrm{t} \mathrm{ha}^{-1}$. The strength requirement and the energy demand showed an exponential behavior with changes in moisture content of sugarcane trash. For moisture content above $28 \%$ (dry basis), the differences between required shearing strengths and energy demands were no longer significant. The maximum shearing strength showed a linear trend which was inversely proportional to the oblique angle of the blade.
\end{abstract}

Key words: mechanization, sugarcane trash, shearing strength

\section{INTRODUÇÃO}

Os dispositivos de corte de materiais vegetais são de grande importância para a agricultura e a pecuária, pois estão sempre presentes no dia-a-dia do meio rural, equipando várias máquinas de corte e acondicionamento de capineiras para alimentação animal, máquinas de colheitas autopropelidas e implementos de preparo e mobilização de solo na presença de palhadas.
As práticas agrícolas que visam mínima mobilização de solo e conservação de restos culturais na sua superfície, têm ganhado destaque nas últimas décadas. Esta afirmação é corroborada por Kushwaha et al. (1983) quando comentam ter aumentado, nos anos mais recentes, as práticas de cultivo mínimo. No entanto, alertam para o fato de que poucos trabalhos têm sido apresentados, do ponto de vista da engenharia, no que se refere à resistência ao corte de restos de culturas, por ser um importante parâmetro no desenvolvimento de 
máquinas para plantio ou trabalho em áreas de cultivo mínimo. Fazem, por fim, algumas considerações a partir da revisão bibliográfica:

- o efeito da velocidade é pequeno ou nulo na energia requerida para o corte de plantas forrageiras por cisalhamento;

- a resistência máxima de corte é diretamente proporcional à densidade de matéria seca e inversamente proporcional à umidade, quando a palha contém altos teores de água;

- a energia requerida para cortar plantas forrageiras é inversamente proporcional ao afiamento da lâmina.

Os pesquisadores utilizaram um aparelho de ensaio de cisalhamento de solo modificado para promover ensaios de cisalhamento em palha de trigo, e velocidades de ensaio baixas, entre 0,005 a $0,015 \mathrm{~mm} \mathrm{~s}^{-1}$, pelo fato de que não dispunham de aparelhos de ensaios que permitissem valores mais elevados de velocidade de corte. Os resultados destas pesquisas demonstraram que a resistência ao cisalhamento da palha não foi influenciada pela velocidade de corte; no entanto, o aumento da umidade da palha até determinado nível (aproximadamente 13\% b.u., para a lâmina com ângulo de afiamento de $30^{\circ}$ e $17,5 \%$ b.u., para a lâmina de $90^{\circ}$ ) provocou um rápido incremento na resistência ao corte, que permaneceu, a partir daí, quase constante. Eles explicaram este comportamento atentando para o fato de que a palha é frágil e menos viscoelástica para baixos teores de umidade e, portanto, mais fácil de se cortar. Para teores elevados de umidade houve incremento na viscoelasticidade da palha, de forma que ocorreram falhas, mas foi difícil produzir a separação das partes.

Os resultados demonstraram, também, que a umidade ideal para cortar a palha de trigo estava na faixa de 8 a $10 \%$ (b.u.) correspondendo a valores mínimos de resistência específica ao corte, de 7 a $11 \mathrm{MPa}$. A magnitude da resistência ao corte foi menor para a lâmina de $30^{\circ}$ em relação à de $90^{\circ}$, demonstrando a importância de seu afiamento.

Os estudos realizados por Halyk \& Hurlbut (1968) já mostravam que o conteúdo de água do material vegetal influencia a resistência desses ao corte. Os seus estudos, utilizando-se de um aparelho tipo pêndulo Charpy, demonstraram que a resistência máxima ao corte de hastes de alfafa foi inversamente proporcional ao conteúdo de água das hastes.

Choi \& Herbach (1986) utilizaram o pêndulo de Charpy e discos lisos de corte de rolamento para estudarem o comportamento dos colmos de milho em corte. Eles observaram que o conteúdo de água dos colmos de milho exerce significante efeito na percentagem de colmos cortados pelo disco, mas tem um pequeno efeito na energia de corte, obtida pelo ensaio com o dispositivo pendular. Colmos úmidos tendem a ser mais difíceis de se cortar pelo disco liso de corte que os colmos secos. Afirmaram, também, que os colmos de milho tendem a ficar mais duros e mais resistentes à flexão com o decréscimo de sua umidade.

Prasad \& Gupta (1975) realizaram ensaios para determinar os valores ótimos de variáveis como ângulo oblíquo, ângulo de corte e velocidade da faca no corte inercial de colmos de milho, utilizando-se de um aparato de corte que funcionava pelo princípio do pêndulo de Charpy. Também avaliaram a influência do diâmetro e umidade do colmo na energia e no requerimento de força de corte. Os seus estudos, para ângulos oblíquos entre 2 e $62^{\circ}$, umidade dos colmos de $78 \%$ (b.u.) e corte normal às fibras, indicaram que a demanda de energia decresceu com o acréscimo do ângulo oblíquo, apresentando um valor mínimo para $32^{\circ}$. O mesmo comportamento foi observado para a força máxima de corte, cujo incremento não foi significativo a partir dos $32^{\circ}$.

A habilidade de uma lâmina para produzir o corte de materiais vegetais depende de vários fatores, classificados em extrínsecos e intrínsecos. Os fatores extrínsecos são aqueles relacionados às condições de operação, como quantidade de massa a ser cortada, taxa de alimentação e os relacionados ao material a ser cortado, como idade das plantas, espécies vegetais que compõem a massa, estado nutricional das plantas e umidade da massa vegetal.

As características intrínsecas à lâmina são aquelas relacionadas às suas dimensões construtivas ou posição de montagem no dispositivo de corte. Segundo Persson (1987) o ângulo do gume $\mathrm{AG}$, definido pelas duas faces do gume da lâmina e a espessura EG do gume da faca, Figura 1A, são as dimensões mais importantes do ponto de vista do corte propriamente dito. No entanto, quando se considera, no estudo, o movimento da faca, tornam-se também importantes os seguintes atributos: espessura da lâmina EL; ângulos de ataque AA, compreendidos entre a face superior do gume da lâmina e o plano "xy"; comprimento da face superior D1, ângulo de limpeza AL, que abrange a face superior do gume e o plano

A.

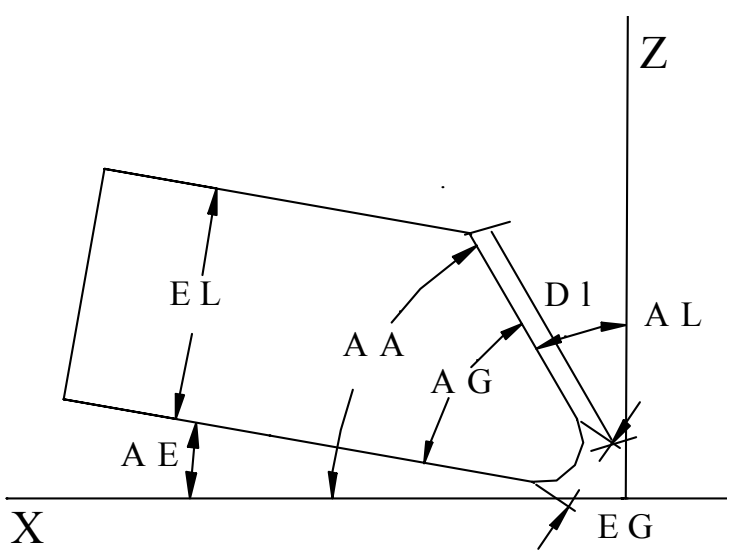

B.

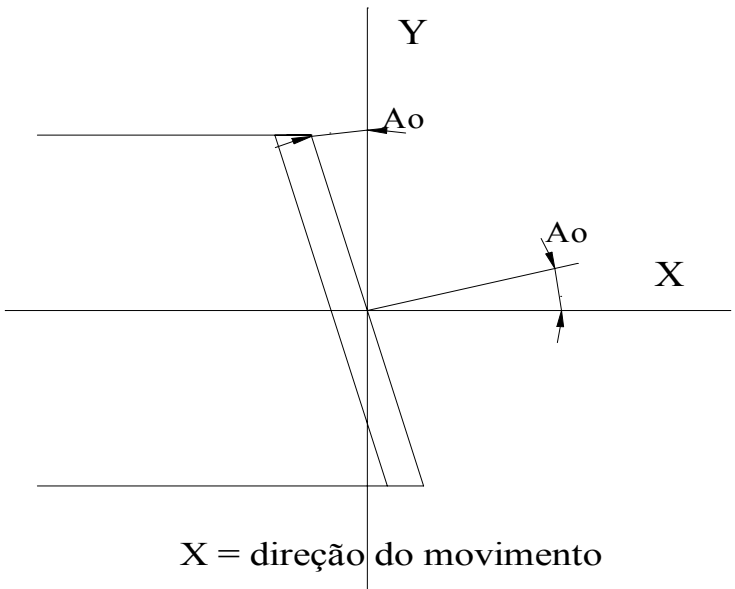

Figura 1. Lâmina de corte mostrando: A - ângulos e dimensões relativos à faca e seu movimento. B - ângulo oblíquo da lâmina 
"zy"; ângulo de escape AE, formado pela face inferior do gume e o plano "xy" e o ângulo oblíquo Ao, formado entre o eixo "y" e a borda cortante do gume. Esses ângulos, que podem ser visualizados na Figura 1, consideram um plano em que o movimento da faca se dá no sentido "x", a largura da faca está no sentido " $y$ " e a normal está no sentido " $z$ ".

As lâminas retas, ou seja, aquelas que não possuem ângulo oblíquo, tocam ao mesmo tempo toda a extensão de seu fio no material a ser cortado, enquanto as que possuem este ângulo penetram gradualmente no material a ser cortado, como pode ser visto na Figura $1 \mathrm{~B}$.

A necessidade de se quantificar as forças e a energia envolvida no corte de material vegetal, em função de variáveis intrínsecas e extrínsecas às lâminas, torna-se necessário, do ponto de vista tecnológico, para o desenvolvimento de ferramentas de máquinas agrícolas. A bibliografia específica na área de cana-de-açúcar traz muito pouca informação referente ao corte do palhiço. Assim, o presente estudo foi o primeiro passo para o conhecimento do comportamento da palha de cana-de-açúcar quanto ao corte. Entende-se por palhiço, de acordo com Rípoli (1991), como sendo a parte do material remanescente no terreno após a operação da colheita de canade-açúcar e constituída de ponteiros, folhas verdes e palha.

Neste sentido, montou-se um experimento que pudesse trazer algumas informações importantes dentro do contexto do estudo, que não foram possíveis de serem levantadas por meio da revisão da bibliografia disponível. O presente trabalho foi, então, desenvolvido com o objetivo de avaliar o comportamento da palha de cana-de-açúcar ao corte, em função da umidade e da espessura de sua camada, bem como do ângulo oblíquo da lâmina.

\section{MATERIAL E MÉTODOS}

A coleta dos dados foi realizada utilizando-se de um aparelho de ensaio montado especificamente para este fim, acoplado a uma prensa mecânica, cuja função foi a de produzir o movimento da faca de corte, a uma velocidade média de 0,31 $\mathrm{m} \mathrm{s}^{-1}$. O equipamento (Figura 2) era composto de uma base sólida de 100 x $70 \mathrm{~mm}$, confeccionada em aço 1020, de onde subiam duas colunas laterais, com $168 \mathrm{~mm}$ de altura, cada qual contendo um canal de formato retangular de dimensões de $4 \mathrm{x}$ $3 \mathrm{~mm}$, disposto no sentido vertical, que servia de guia para a lâmina em seu movimento retilíneo alternado. Na parte posterior da base estava instalada a contra-faca.

A prensa gerava um ciclo de movimento retilíneo alternado, com curso de $45 \mathrm{~mm}$, de forma que a lâmina pudesse descer através da camada de palha e retornar à sua posição original. Entre a prensa e a lâmina foi acoplada a célula de carga para que a força requerida no corte da palha pudesse ser mensurada. Sobre a base foi colocada a caixa de ensaios, que se encaixava nas colunas por meio de canais de seções retangulares, dispostos horizontalmente. A caixa de ensaios apresentava um fundo falso, por onde a lâmina transpassava, para efetuar o corte da amostra, tendo a contra-faca como apoio do material ensaiado.

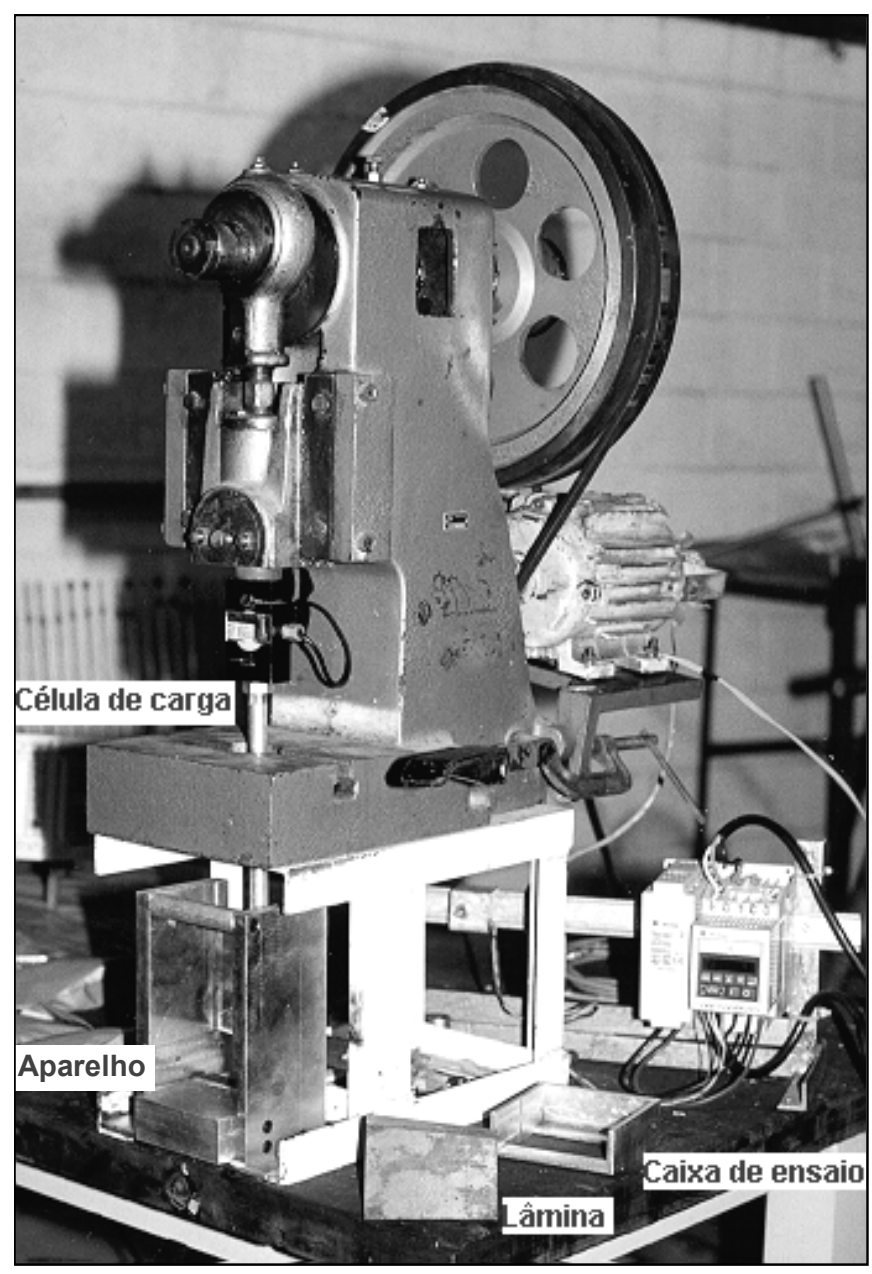

Figura 2. Componentes principais do equipamento de ensaio montado para obtenção dos dados de força de corte

As lâminas utilizadas nos experimentos apresentavam as seguintes características: comprimento de $100 \mathrm{~mm}$; espessura de $4 \mathrm{~mm}$ e ângulo do gume de $15^{\circ}$. A caixa de ensaio do aparelho, com área útil de $10^{4} \mathrm{~mm}^{2}$, permitia a variação da quantidade de palha das amostras ensaiadas. Todos os experimentos foram realizados na presença de contra-faca, utilizando-se de palha da variedade de cana IAC 554.

O estudo para atender aos objetivos propostos neste trabalho foi dividido em três partes, em que cada uma se caracterizou por um experimento independente, o primeiro foi desenvolvido com o objetivo de se verificar o comportamento da força e energia de corte, em função da quantidade de palha de cana, enquanto os segundo e terceiro experimentos buscaram avaliar, especificamente, a influência da umidade da palha da cana e o ângulo oblíquo da lâmina, no requerimento de força e na demanda de energia, para efetuar o corte da palha da cana.

O primeiro, de caráter mais abrangente, foi montado num esquema fatorial, com dois tipos de lâmina (uma sem ângulo oblíquo e a outra com ângulo oblíquo de $10^{\circ}$ ) e 4 quantidades de palha de cana (referentes a 4, 8, 12 e $16 \mathrm{t} \mathrm{ha}^{-1}$ ). Foram realizados 20 ensaios (repetições) para cada nível de quantidade de palha versus tipo de lâmina, totalizando 160 parcelas experimentais. A quantidade de palha aqui utilizada é motivada pela variação da quantidade do palhiço, em canaviais brasileiros. 
Para montagem das amostras, a palha de cana foi preparada e disposta da seguinte maneira: as folhas secas de cana (palha) foram divididas em 3 segmentos: bainha, parte inferior e parte superior do limbo. Cada amostra levada ao aparelho para ensaio era composta por camadas desses três segmentos, sorteados ao acaso. A disposição das porções de folhas, em cada camada, era também sorteada, entre três opções: $0^{\circ}, 45^{\circ} \mathrm{e} 90^{\circ} \mathrm{em}$ relação ao eixo transversal da caixa de ensaio. Para compor uma amostra de ensaio, a caixa ia recebendo camadas de porções de palha, até atingir o peso correspondente à quantidade de palha/ha desejada. Esses procedimentos foram adotados para que se pudesse simular as condições da disposição do palhiço no campo. Uma amostra da palha utilizada em cada ensaio era pesada imediatamente e levada à estufa, para determinação do teor de água da palha.

No segundo experimento adotou-se um delineamento inteiramente casualizado, procurando-se avaliar, especificamente, a influência do teor de água da palha da cana na força e na energia requerida para o corte. Neste experimento utilizouse a porção inferior do limbo foliar, disposto a $90^{\circ}$ na quantidade de palha relativa a $10 \mathrm{t} \mathrm{ha}^{-1}$. A lâmina de corte para esse experimento possuía ângulo oblíquo de $5^{\circ}$ e foram realizados nove ensaios (repetições) para cada um dos quatro níveis de umidade da palha avaliados $(9,6,28,4,41,0$ e $69,7 \%)$.

No último experimento, também por meio de um delineamento inteiramente casualizado, procurou-se verificar a influência específica do ângulo oblíquo da lâmina no requerimento de força e energia necessária para o corte da palha da cana. Para tanto, realizaram-se oito ensaios (repetições) para cada uma das três lâminas estudadas (ângulos oblíquos de 0,5 e $10^{\circ}$ ). As condições de ensaios foram as mesmas do segundo experimento, com exceção da umidade da palha, que foi mantida em torno de $14 \%$. Nos dois últimos experimentos também foi realizado controle de umidade da palha de cada ensaio, a exemplo do primeiro experimento.

As forças aplicadas nas lâminas de corte foram medidas por meio de um transdutor de força, tipo célula de carga, com $10 \mathrm{kN}$ de fundo de escala e erro total combinado de $0,5 \%$. Os valores lidos em cada ensaio, com duração de um segundo, foram registrados por um sistema de aquisição de dados, a uma taxa de aquisição de $9.600 \mathrm{~Hz}$. Os arquivos com os dados gerados foram convertidos pelo programa computacional "Catman", desenvolvido pela HBM, para o formato texto, permitindo que os registros pudessem ser lidos por outros aplicativos. Utilizando-se do programa computacional "Matlab", desenvolvido pela MathWorks Incorporation, os dados obtidos nos ensaios foram tratados para se obter a máxima força registrada em cada ensaio.

Nos dois últimos experimentos, nos quais se analisava a influência da umidade e do ângulo oblíquo da lâmina foi levantada, também, a demanda de energia para o corte; para tanto, usou-se a técnica de integração por trapézios e, com o auxílio de uma pequena rotina computacional, implementada no "Matlab", levantou-se a área sob a curva da força de corte versus deslocamento da lâmina, que corresponde à energia total demandada no corte.

\section{RESULTADOS E DISCUSSÃO}

Para se comparar os valores de força de corte e energia obtidos, foram levantadas algumas dimensões das lâminas e calculado, de acordo com metodologia, um Fator de Corte $\left(F_{c}\right)$ apresentado na Tabela 1, segundo a metodologia apresentada por Bianchini (2002).

Os valores obtidos para $\mathrm{F}_{\mathrm{c}}$, como se observa, são bastante próximos, permitindo que os dados encontrados nos ensaios que envolveram lâminas com ângulos oblíquos diferentes, possam ser comparados. Observa-se, também, que a lâmina

Tabela 1. Dimensões e valores do ângulo do gume, conforme Figura 1 e fator de corte $\left(\mathrm{F}_{\mathrm{c}}\right)$ obtidos para as lâminas utilizadas nos ensaios

\begin{tabular}{|c|c|c|c|c|c|}
\hline \multirow{2}{*}{$\begin{array}{c}\text { Lâminas } \\
\text { Ao }\end{array}$} & \multicolumn{3}{|c|}{ Dimensões (mm) } & \multirow{2}{*}{$\begin{array}{c}\mathrm{AG}^{*} \\
\text { (graus) }\end{array}$} & \multirow{2}{*}{$\begin{array}{c}\mathrm{F}_{\mathrm{c}} \\
\left(\mathrm{mm}^{-2}\right)\end{array}$} \\
\hline & Dl & EL* & $\mathrm{EG}^{*}$ & & \\
\hline $0^{\circ}$ & 15,15 & 3,97 & 0,05 & 15,00 & 5,04 \\
\hline $5^{\circ}$ & 14,85 & 3,95 & 0,04 & 15,25 & 6.33 \\
\hline $10^{\circ}$ & 14,95 & 4,03 & 0.06 & 15,42 & 4,14 \\
\hline
\end{tabular}

* Por se tratar de lâmina com afiamento de um só lado, os valores de AG e EL foram multiplicados por 2 e o valor de EG é a metade do valor obtido no cálculo

apresentava boa afiação, já que os valores de EG são pequenos, da ordem de centésimos de milímetros.

Os arquivos de dados, oriundos de cada ensaio com duração de um segundo, forneciam 9600 valores de força. Para avaliação dos dados foi preciso depurar estes arquivos de forma a se obter apenas o tempo efetivo do ensaio. A Figura 3 mostra dois exemplos de ensaios do primeiro experimento, um com lâmina de $0^{\circ}$ e o outro com lâmina de $10^{\circ}$ de ângulo oblíquo, realizados com quantidade de palha correspondente a $12 \mathrm{tha}^{-1} \mathrm{e}$ teor de água de $16 \%$.

As curvas da Figura 3 se aproximam muito da curva típica de corte de material fibroso na presença de contra-faca, apresentada por Persson (1987). Em um primeiro instante, a palha é comprimida, resultando em um aumento gradual da força, porém o corte ainda não tem início. Após certo grau de compressão, a palha passa a não mais resistir à ação cisalhante

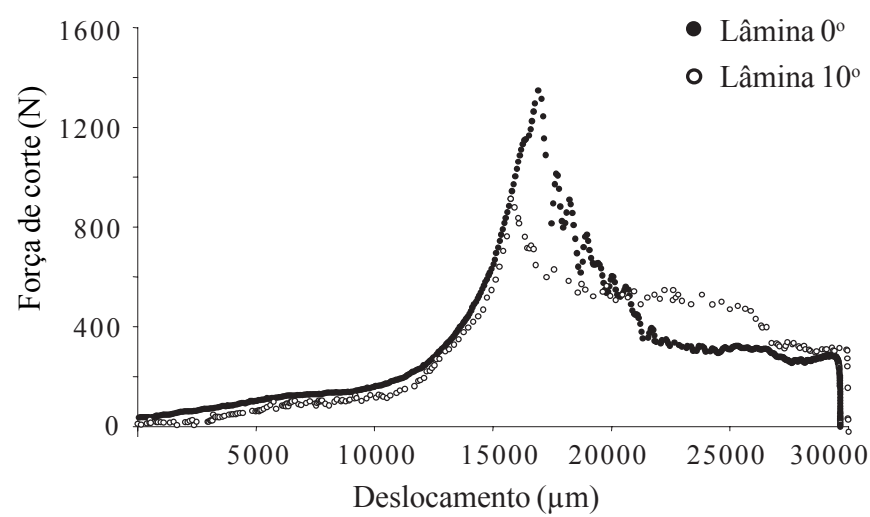

Figura 3. Forças de corte, em Newton, em função do deslocamento, em micrômetros, das lâminas de $0^{\circ}$ e $10^{\circ}$ de ângulo oblíquo, obtidas em ensaios com palha na quantidade correspondente a $12 \mathrm{t} \mathrm{ha}^{-1} \mathrm{e}$ teor de água de $16 \%$ 
da faca e o processo de corte efetivamente tem início. Após o término do corte, a força tende a zero.

Os resultados obtidos do primeiro experimento, com umidade média de $18,7 \%$ b.s e coeficiente de variação de $14,5 \%$, são mostrados na Figura 4 . As forças máximas de corte da palha de cana-de-açúcar apresentaram tendência linear e crescente, com médias de 760,4 e 1355,9 N para a lâmina sem ângulo oblíquo e de 396,6 e $997,3 \mathrm{~N}$ para a lâmina com ângulo oblíquo de $10^{\circ}$, nas quantidades de palha de 4 e $16 \mathrm{tha}^{-1}$, respectivamente. $\mathrm{O}$ incremento de força para as lâminas de 0 e $10^{\circ}$ de ângulo oblíquo foi, respectivamente, da ordem de 47,9 e 51,2 $\mathrm{N}$ para cada tha ${ }^{-1}$ de palha acrescida.

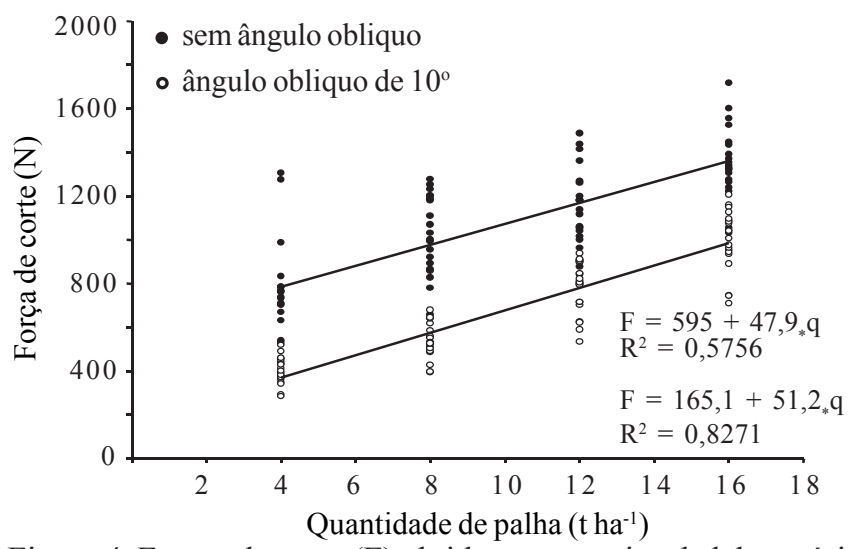

Figura 4. Forças de corte (F) obtidas nos ensaios de laboratório para as lâminas com ângulos oblíquos de $0^{\circ}$ (sem ângulo) e de $10^{\circ}$, em função da variação da quantidade de palha (q)

Os valores dos coeficientes angulares das equações de regressão obtidas são próximos entre si, demonstrando haver diferença na força de corte, quase constante, da ordem de 360 $\mathrm{N}$, entre os valores obtidos para as lâminas, no intervalo de quantidade de palha estudado. Observa-se que houve redução (significativa a nível de $1 \%$ de probabilidade) na força máxima de corte quando, se utilizou a lâmina com ângulo oblíquo de $10^{\circ}$, em relação àquela sem ângulo.

Os coeficientes de determinação das equações de regressão foram considerados bons, uma vez que se trata de material biológico, que pode apresentar grandes variações de constituição entre duas porções de uma mesma unidade biológica; no entanto, deve-se lembrar que a preocupação primeira deste experimento foi a de se obter informações a respeito do comportamento do palhiço quando atacado por uma ferramenta de corte, em condições de campo. Desta forma, já era esperada grande variação nos valores obtidos entre as repetições de um mesmo tratamento.

No segundo experimento, realizado com quatro níveis de umidade $(9,6,28,4,41,0$ e $69,7 \%)$ foi necessário, para efeito de comparação dos dados, determinar a força específica de corte e a energia específica demandadas. Esta exigência decorre do fato de que, ao se variar a umidade do material, mantendo-se constante a quantidade de massa úmida utilizada nos ensaios, há diferenças significativas entre as massas secas. A força específica de corte $\left(\mathrm{MPa}-\mathrm{N} \mathrm{mm}^{-2}\right.$ de seção transversal ao

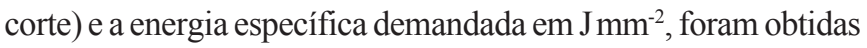

considerando-se a densidade do material como sendo de 1,45 $\mathrm{g} \mathrm{cm}^{-3}$, conforme Persson (1987).

Os resultados de força máxima específica, obtidos para este experimento e apresentados na Figura 5, mostram que ela variou em função da umidade da palha, sendo que os valores médios encontrados foram de 7,7,11,2, 10,7 e 10,6 MPa, para umidades da palha de 9,6, 28,4, 41 e $69,7 \%$, respectivamente.

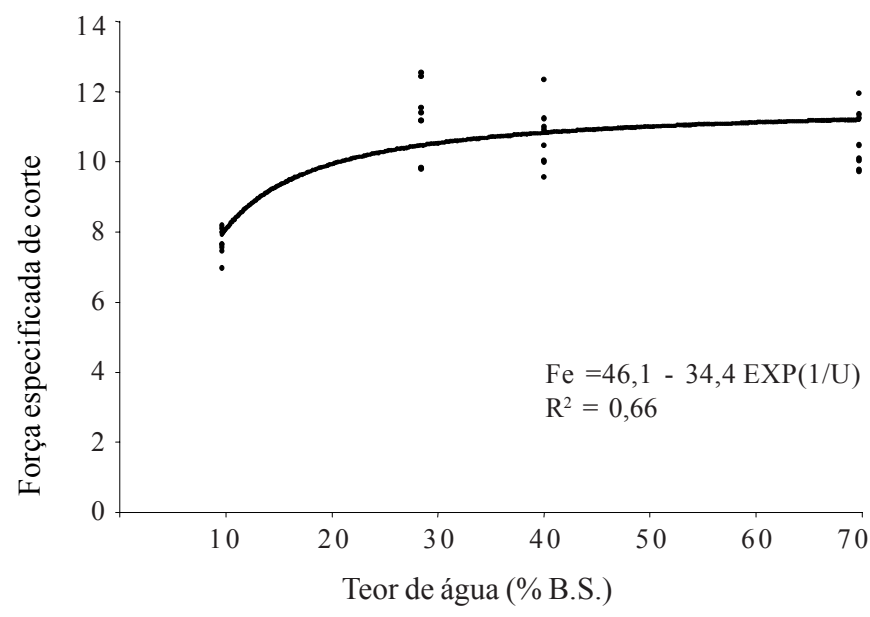

Figura 5. Força específica de corte (Fe), em função do teor de água da palha da cana (U) e lâmina com ângulo oblíquo de $5^{\circ}$

O modelo de regressão que melhor se ajustou foi o exponencial, com coeficiente de determinação de 0,66. Este modelo determina tendência crescente, porém com uma taxa de incremento cada vez menor, de forma que as variações na força específica sejam pequenas quando a umidade da palha atinge níveis superiores a $28,4 \%$. Observa-se, portanto, que, a partir de $28,4 \%$ de umidade da palha, não houve mais incremento na força específica requerida para o corte.

Prasad \& Gupta (1975) encontraram, em seus estudos, uma relação inversamente proporcional entre a máxima força de corte inercial e a umidade de colmos de milho. A diferença entre os comportamentos pode ser explicada pelo tipo de corte. O corte inercial não depende de contra-faca, uma vez que a inércia do próprio material a ser cortado é que resiste à ação de deslocamento provocada pela lâmina de corte sendo, assim, altamente dependente da velocidade de corte. O corte com contra-faca não depende da velocidade de corte.

Outro fato que pode explicar a divergência entre os resultados obtidos é o de que os autores citados trabalharam com colmos de milho com idade de 70 dias; logo, os tecidos estavam vivos e, conseqüentemente, túrgidos. A pressão dos líquidos internos à parede celular favorece o processo de corte, como relata Persson (1987). O presente trabalho foi realizado com palha de cana-de-açúcar, portanto, tecido morto. Neste caso, a umidade absorvida pelas fibras vegetais não provoca a mesma turgidez encontrada no tecido vivo mas, por outro lado, torna-a maleável. A isto, soma-se a existência de uma folga que havia entre faca e contra-faca, comum neste tipo de dispositivo de corte, onde algum material se alojava durante o processo de corte, como já discutido. Desta forma, a força de corte não foi representada exclusivamente pelo cisalhamento puro, porque no processo alguma palha acabava sendo separada, também, 
por outras forças, como a de dilaceramento. Este fato se intensificou com o aumento do teor de água, uma vez que há incremento da maleabilidade da palha com o aumento do seu conteúdo de água.

Observa-se, na Figura 5, que a partir da umidade de 28,4\% em base seca, as forças máximas específicas de resistência da palha ao corte já não mais apresentaram diferenças significativas, demonstrando que, a partir de uma umidade, a quantidade de água presente na palha praticamente não mais interferiu na força de corte. A palha pouco úmida $(9,6 \%$ b.s. $)$ ofereceu resistência específica ao corte de 7,7 $\mathrm{MPa}$, significativamente menor em relação aos outros níveis de umidade estudados. Comportamento semelhante foi observado por Kushwaha et al. (1983) que encontraram, para a palha de trigo com umidade entre 8 a $10 \%$ em base úmida, valores de força específica de corte de $7 \mathrm{MPa}$ para lâmina com ângulo de afiamento de $30^{\circ}$.

O comportamento das forças de corte observado para a palha de cana, pode ser explicado pelo fato de que a palha, quando seca, ou seja, com pouca quantidade de água, apresenta comportamento elástico quanto ao corte, que se traduz em uma palha mais quebradiça e mais fácil de ser cortada. Com o incremento da quantidade de água presente a palha passa a ter comportamento cada vez mais visco-elástico, tornando-se mais maleável e mais difícil de ser cortada.

A energia específica demandada para o corte em função do teor de água apresentou comportamento semelhante ao da força de corte, como pode ser observado na Figura 6 . A demanda de energia específica média para cortar a palha da cana apresentou um valor mínimo na umidade, de $9,6 \%$, que foi de $0,10 \mathrm{~J} \mathrm{~mm}^{-2}$, significativamente menor que os valores demandados para os outros níveis de umidade.

As quantidades de energia demandada para as umidades de 28,4, 41,0 e 69,7\% foram, respectivamente, de $0,14 \mathrm{~J}, 0,13 \mathrm{Je}$ de $0,14 \mathrm{~J} \mathrm{~mm}^{-2}$. O modelo de regressão que melhor se ajustou para explicar o comportamento da demanda de energia específica, em função da variação da umidade foi, a exemplo da demanda de força específica, o exponencial, com um fator de determinação de 0,78 . O incremento na demanda de energia específica foi praticamente nulo a partir da umidade de $28,4 \%$, como pode ser observado, ainda, na Figura 6.

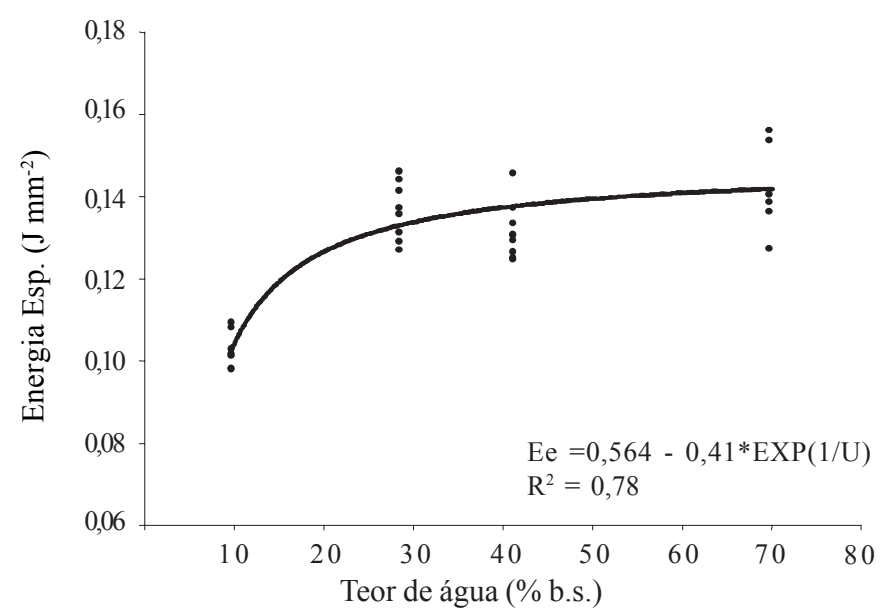

Figura 6. Energia específica de corte (Ee), em função do teor de água da palha da cana (U) e lâmina com ângulo oblíquo de $5^{\circ}$
Os resultados demonstraram que existe uma variação significativa na demanda de energia para cortar a palha da cana, quando se varia o seu conteúdo de água. A energia específica demandada para cortar a palha com teor de água superior a $28,4 \%$, foi $40 \%$ superior àquela demandada para cortar palha com 9,6\% de umidade, em base seca. Esses resultados mostraram que é recomendável, do ponto de vista da demanda energética, cortar a palha de cana seca; no entanto, as condições de operação dos dispositivos de corte variam muito no dia-a-dia do meio rural, não permitindo que se trabalhe apenas em condições ótimas de operação. Neste sentido e se analisando puramente a questão energética, não se justifica aguardar a secagem do palhiço para se proceder ao cultivo quando não há tempo para que ele atinja níveis próximos de $10 \%$.

Os resultados do terceiro experimento, onde se variou o ângulo oblíquo da lâmina de corte, estão apresentados na Figura 7. Eles demonstraram diferenças significativas entre as lâminas, no que se refere à máxima força específica de corte demandada.

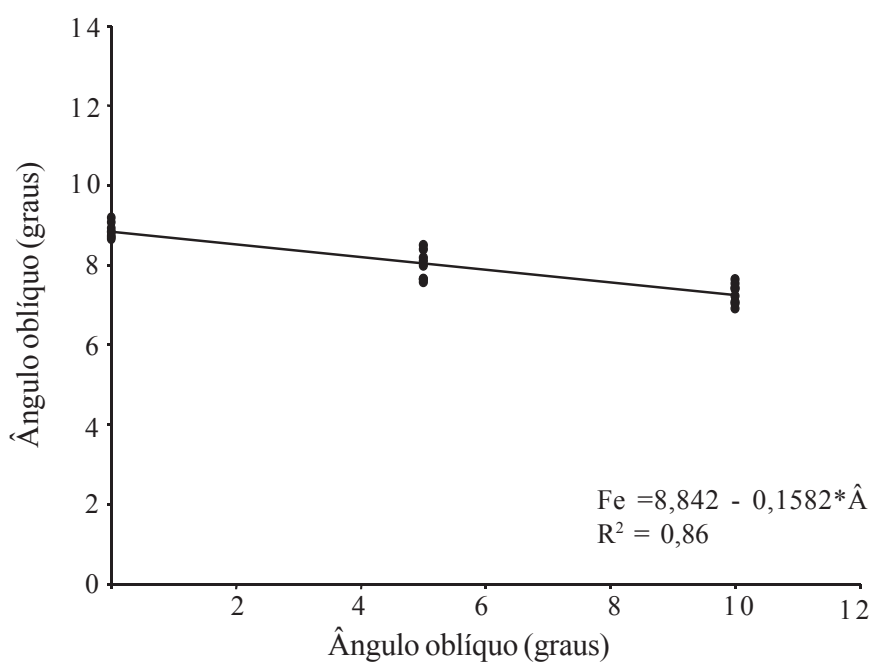

Figura 7. Força específica de corte (Fe), em função do ângulo oblíquo da lâmina (Ao), para palha com teor de água de 14\%

O modelo linear, com coeficiente de determinação de 0,86 e tendência inversamente proporcional, foi o que melhor se ajustou para explicar o comportamento da máxima força específica de corte requerida em função do ângulo oblíquo da lâmina. A lâmina sem ângulo oblíquo apresentou uma demanda média para esta força igual a $8,86 \mathrm{MPa}$, enquanto as lâminas com 5 e de $10^{\circ}$ de ângulo oblíquo apresentaram, respectivamente, 8 e 7,28 MPa de força específica. Esses resultados mostraram que é benéfica a existência deste ângulo em ferramentas para corte de palha de cana-de-açúcar, do ponto de vista da força requerida para o corte e, conseqüentemente, da potência instantânea exigida.

A força específica máxima encontrada pela lâmina com $10^{\circ}$ de ângulo oblíquo, foi $18 \%$ inferior à requerida pela lâmina sem ângulo. Este ângulo, formado pela borda cortante da lâmina e pela linha paralela à superfície do material a ser cortado, reduz a força específica máxima de corte porque provoca um corte progressivo e contínuo, ao contrário da lâmina reta, que produz um corte abrupto do material. A lâmina sem ângulo oblíquo solicita uma força grande, um curto período de tempo que coincide com o momento em que ocorre o início do corte, já 
que ele acontece simultaneamente em toda a extensão da lâmina. Quando a lâmina apresenta ângulo oblíquo, a parte mais avançada inicia o corte antes da parte mais retraída, de forma que o pico da solicitação de força fica atenuado. Esta atenuação será, dentro de certos limites, tanto maior quanto maior for o ângulo oblíquo da lâmina.

Prasad \& Gupta (1975) estudaram a variação da força específica máxima em função de ângulos oblíquos entre 2 e $62^{\circ}$. O trabalho demonstrou que ângulos oblíquos entre $32 \mathrm{e}$ $62^{\circ}$ não influenciaram na força específica máxima de corte, mas que, entre 2 e $32^{\circ}$, ocorreu um incremento linear e inversamente proporcional desta força. Os valores encontrados por eles para a força específica máxima de corte de colmos de milho, situaramse em torno de $0,7 \mathrm{MPa}$ para o ângulo de $2^{\circ}$ e $0,15 \mathrm{MPa}$ para o ângulo de $32^{\circ}$. Ressalta-se que a força específica de que os autores se referiram baseia-se na área de seção transversal do colmo indeformado, ou seja, a área ocupada por sólidos e não sólidos que constituem os colmos de milho. Os autores explicaram que, para ângulos oblíquos pequenos, o efeito da ação de cunha da lâmina é grande, enquanto para valores altos desses ângulos ocorrem deslizamentos que, por sua vez, minimizam o efeito de cunha.

A análise da quantidade de energia envolvida no processo, por outro lado, não mostrou diferenças significativas entre as lâminas estudadas. A Figura 3 representa ensaios realizados, cujas áreas, sob as curvas, equivalem à energia necessária para cortar a palha de cana. $\mathrm{O}$ exemplo mostra que as áreas sob as curvas de força de corte momentâneas, para as lâminas de $0^{\circ}$ e de $10^{\circ}$ de ângulo oblíquo, não parecem ser tão diferentes. $\mathrm{Na}$ verdade, a análise de variância das quantidades de energia requeridas pelas lâminas estudadas não mostrou diferenças significativas, em nível de $5 \%$ de probabilidade pelo teste " $F$ ", entre suas médias. As lâminas com 0,5 e $10^{\circ}$ de ângulo oblíquo apresentaram, respectivamente, uma demanda de energia de $0,098,0,1$ e $0,104 \mathrm{~J}_{*} \mathrm{~mm}^{-2}$. Esses resultados apontaram que a variação deste ângulo não influenciou a quantidade de energia demandada para cortar a palha da cana, mas apresentou diferenças significativas do ponto de vista da demanda de força máxima de corte.

Nos processos de corte, que envolvem lâminas com ângulos oblíquos, aparece uma força lateral que tende a deslocar o material para fora da linha de atuação da faca. Esta força é equilibrada pelas forças de atrito entre o material a ser cortado e o metal da lâmina. Com o aumento do ângulo oblíquo, a componente lateral assume valores elevados e as forças de atrito passam a não serem mais eficientes para segurar o material na posição de corte. No presente trabalho, o maior ângulo oblíquo utilizado para a lâmina foi o de $10^{\circ}$, justamente para evitar que houvesse deslocamento lateral da palha, que causaria um acúmulo deste material na porção mais retraída da lâmina. Caso isto ocorresse, os ensaios seriam invalidados, pois haveria uma concentração de força no final dos mesmos, o que contrariaria o esperado. Os resultados mostraram que não houve deslocamento lateral da palha durante a execução dos ensaios, pois as curvas apresentadas pela lâmina de $10^{\circ}$ mostraram comportamento semelhante ao esperado, a exemplo daqueles apresentados na Figura 3.

\section{CONCLUSÕES}

1. A diferença na força máxima de corte entre as lâminas com 0 e $10^{\circ}$ de ângulo oblíquo foi da ordem de $350 \mathrm{~N}$, para quantidades de palha entre 4 e 16 tha $^{-1}$.

2. A força específica de corte, em função do teor de água da palha da cana-de-açúcar, apresentou comportamento exponencial.

3. A demanda de energia específica, em função do teor de água da palha da cana-de-açúcar, mostrou comportamento exponencial.

4. Não houve diferenças significativas na força máxima e na energia requeridas para cortar a palha da cana com teor de água superiores a $28 \%$ b.s.

5. Foi mais fácil cortar a palha de cana quando seu teor de água estava próximo de $10 \%$ b.s.

6. A força máxima de corte apresentou tendência linear e inversamente proporcional ao ângulo oblíquo da lâmina.

7. A energia específica demandada para cortar a palha da cana-de-açúcar não foi influenciada pelo ângulo oblíquo da faca.

\section{LITERATURA CITADA}

Bianchini, A. Desenvolvimento teórico experimental de disco de corte dentado passivo, para corte de palhiço em canade-açúcar. Campinas: UNICAMP. 2002. 218p. Tese Doutorado

Choi, C.H.; Erbach, D.C. Cornstalk residue shearing by rolling coulters. Transaction of the ASAE, St. Joseph, v.29, n.6, p.1530-1535, 1986.

Halyk, R.M; Hurlbut L.W. Tensile and shear strength characteristics of alfalfa stems. Transaction of the ASAE, St. Joseph, v.11, n.2, p.256-257. 1968.

Kushwaha, R.L.; Vaishnav, A.S.; Zoerb, G.C. Shear strength of wheat straw. Canadian Agricultural Engineering, Winnipeg, v.25, n.2, p.163-166, 1983 .

Persson, S. Mechanics of cutting plant material. St. Joseph: American Society of Agricultual Engineers, 1987. ASAE Monograph Number 7

Prasad, J.; Gupta, C.P. Mechanical properties of maize stalk as related to harvesting. Journal Agriculture Engineering Research, London, v.20, p.79-87, 1975.

Rípoli, T.C. Utilização do material remanescente da colheita de cana-de-açúcar (Saccharum spp) - Equacionamento dos balanços energético e econômico. Piracicaba: ESALQ, 1991. 150 p. Tese Livre Docência 